\title{
TEKNIK PENGOLAHAN HASIL ASESMEN: TEKNIK PENGOLAHAN DENGAN MENGGUNAKAN PENDEKATAN ACUAN NORMA (PAN) DAN PENDEKATAN ACUAN PATOKAN (PAP)
}

\author{
Khairuddin Alfath \\ E-mail: khairuddin475@gmail.com \\ Mahasiswa Magister Pendidikan Agama Islam \\ Universitas Islam Negeri Sunan Kalijaga Yogyakarta \\ Fajar Fauzi Raharjo \\ E-mail: fajarfauzi20@yahoo.co.id \\ Mahasiswa Magister Pendidikan Agama Islam \\ Universitas Islam Negeri Sunan Kalijaga Yogyakarta
}

\section{Abstrak}

Artikel ini menginformasikan tentang teknik pengolahan penilaian dengan menggunakan pendekatan Penilaian Acuan Norma (PAN) dan pendekatan Penilaian Acuan Patokan (PAP). Skor mentah hasil belajar siswa perlu diinterpretasikan agar dapat menjadi nilai yang bermakna. Proses inilah yang dinamakan penilaian. Agar guru tidak melakukan penilaian dengan asal-asalan, maka diperlukan suatu patokan atau standar. Dalam asesmen pendidikan, terdapt dua pendekatan yang digunakan dalam pengolahan nilai, yaitu pendekatan Penilaian Acuan Norma (PAN) dan pendekatan Penilaian Acuan Patokan (PAP). Melalui artikel ini disuguhkan konsep dasar pendekatan Penilaian Acuan Norma (PAN) dan pendekatan Penilaian Acuan Patokan (PAP), diantaranya adalah pengertian, karakteristik, tujuan dan manfaat, prosedur penggunaan, kelebihan dan kekurangan, serta perbedan antara kedua pendekatan tersebut. Ditambahkan pula contoh aplikasinya dalam Microsoft excel. Selain itu, dibahas pula tentang Kriteria Ketuntasan Minimum (KKM).

Kata Kunci: Teknik, Asesmen, Pendekatan, Acuan, Norma, Patokan

\section{Abstract}

This article informs about the assessment processing technique using the Norm Reference approach and the Benchmark Reference Assessment approach. The raw score of student learning outcomes needs to be interpreted so that it can be a meaningful value. This process is called valuation. So that the teacher does not carry out 
Khairuddin Alfath, Fajar Fauzi Raharjo : Teknik Pengolahan Hasil Asesmen: Teknik Pengolahan dengan Menggunakan Pendekatan Acuan Norma (PAN) dan

Pendekatan Acuan Patokan (PAP)

the assessment carelessly, a standard or standard is needed. In the education assessment, two approaches were used in the processing of values, namely the Norm Reference approach and the Benchmark Reference Assessment approach. Through this article the basic concepts of the Norm Reference approach and the Benchmark Reference Assessment approach are presented, including understanding, characteristics, goals and benefits, use procedures, advantages and disadvantages, and differences between the two approaches. Also added is an example application in Microsoft Excel. In addition, also discussed the Minimum Completion Criteria.

\section{Keywords: Technique, Assessment, Approach, Reference, Norm, Benchmark}

\section{A. PENDAHULUAN}

Penilaian adalah bagian yang sangat penting dalam proses evaluasi. Penilaian hasil belajar peserta didik yang dilakukan oleh guru selain untuk memantau proses kemajuan dan perkembangan hasil belajar peserta didik sesuai dengan potensi yang dimiliki, juga sekaligus umpan balik kepada guru agar dapat menyempurnakan perencanaan dan proses program pembelajaran. Namun jika proses penilaian yang dilakukan oleh guru asal-asalan dan tanpa arah yang jelas, maka pada akhirnya akan menghasilkan informasi tentang hasil pencapaian pembelajaran peserta didik yang tidak akurat dan tidak sesuai dengan apa yang ada di lapangan.

Sebelumnya, perlu dijelaskan terlebih dahulu tentang skor dan nilai agar tidak terjadi kesalahpahaman. Skor adalah hasil pekerjaan memberikan angka yang diperoleh dengan jalan menjumlahkan angka-angka bagi setiap butir item yang telah dijawab oleh testee dengan betul, dengan memperhitungkan bobot jawaban betulnya. ${ }^{1}$

1 Sukiman, Pengembangan Sistem Evaluasi, (Insan Madani: Sleman, 2012), hlm. 252. 
Khairuddin Alfath, Fajar Fauzi Raharjo : Teknik Pengolahan Hasil Asesmen: Teknik Pengolahan dengan Menggunakan Pendekatan Acuan Norma (PAN) dan Pendekatan Acuan Patokan (PAP)

Adapun nilai adalah angka atau pun huruf yang merupakan hasil ubahan dari skor yang sudah dijadikan satu dengan skor-skor lainnya, serta disesuaikan pengaturannya dengan standar tertentu. ${ }^{2}$

Skor yang diperoleh dari sebuah tes baru akan bermakna jika ditafsirkan berdasarkan suatu patokan atau berdasarkan suatu norma. Ini lah yang disebut dengan penilaian. Pengolahan nilai-nilai menjadi nilai akhir seorang siswa dapat dilakukan dengan mengacu kepada kriteria atau patokan tertentu. Menurut Woodworth (1961) ada dua jenis pedoman yang bisa digunakan untuk menentukan nilai (mengubah skor menjadi nilai) sebagai hasil evaluasi yaitu: 1. Dengan cara membandingkan skor yang diperoleh seorang individu (mahasiswa) dengan suatu standar yang sifatnya mutlak (absolut). 2. Dengan cara membandingkan skor yang diperoleh seorang individu (mahasiswa) dengan skor yang diperoleh mahasiswa lainnya dalam kelompok tes tersebut. ${ }^{3}$

Dalam tulisan ini, teknik pengolahan nilai disajikan dalam susunan yang sederhana yang meliputi pengertian, karakteristik, tujuan dan manfaat, prosedur penggunaan, kelebihan dan kekurangan, serta perbedan antara kedua pendekatan tersebut. Disertai pula dengan contoh penerapannya. Adapun penerapannya dibantu dengan aplikasi Microsoft excel, dengan asumsi bahwa setiap aplikasi ini cenderung familiar di kalangan pendidik, dan aplikasinya cenderung mudah untuk digunakan. Selain itu, dibahas pula tentang Kriteria Ketuntasan Minimum (KKM).

2 Ibid., hlm. 252.

3 Daeng Idris, "Teknik Penilaian Pembelajaran Dengan Menggunakan Passing Grade", Jurnal Matematika, Statistika dan Komputasi, vol. IV, No. 1, 26-29 Juli 2017, hlm. 26. 
Khairuddin Alfath, Fajar Fauzi Raharjo : Teknik Pengolahan Hasil Asesmen: Teknik Pengolahan dengan Menggunakan Pendekatan Acuan Norma (PAN) dan

Pendekatan Acuan Patokan (PAP)

\section{B. PEMBahasan}

1. Teknik Penskoran Hasil Pembelajaran

a. Ranah Kognitif

1) Menentukan skor pada soal Esai

Tes bentuk esai adalah sejenis tes kemajuan belajar yang memerlukan jawaban yang bersifat pembahasan atau uraian kata-kata. Ciri-ciri pertanyaannya didahului dengan kata-kata seperti; uraikan, jelaskan, mengapa, bagaimana, bandingkan, simpulkan, dan sebagainya. ${ }^{4}$

Menentukan skor dapat dipilih dari beberapa skala pengukuran, misalnya skala 1-4, 1- 10 dan 1-100. Ada beberapa hal yang perlu diperhatikan, antara lain: 5

a) Sebaiknya jangan memberikan skor nol

b) Mulailah skoring dari angka 1 . Semakin tinggi skala pengukuran yang digunakan maka hasilnya halus dan akurat. Pemberian skor ini berlaku sama untuk semua nomor soal.

c) Setelah menetapkan skor langkah selajutnya adalah menetapkan pembobotan sesuai dengan tingkat kesukaran soal.

d) Sebaiknya gunakan skala 1-10, misalnya soal yang mudah diberi bobot 2 , sedang bobotnya 3 , dan soal soal yang sulit bobotnya 5 .

4 Suharsimi Arikunto, Dasar-Dasar Evaluasi Pendidikan, (Jakarta: Bumi Aksara, 2013), hlm. 177.

5 Elis Ratnawulan dan Rusdiana, Evaluasi Pembelajaran, Cet. Ke-2, ( Bandung: Pustaka Setia, 2017), hlm. 235 
Khairuddin Alfath, Fajar Fauzi Raharjo : Teknik Pengolahan Hasil Asesmen: Teknik Pengolahan dengan Menggunakan Pendekatan Acuan Norma (PAN) dan Pendekatan Acuan Patokan (PAP)

Contoh:

\begin{tabular}{|c|c|c|c|c|}
\hline No & Nomor Soal & Nilai & Bobot & Total Nilai \\
\hline 1 & 1 & 3 & 2 & 6 \\
\hline 2 & 2 & 5 & 5 & 25 \\
\hline 3 & 3 & 8 & 3 & 24 \\
\hline 4 & 4 & 6 & 3 & 18 \\
\hline 5 & 5 & 5 & 3 & 15 \\
\hline 6 & 6 & 8 & 2 & 16 \\
\hline & & $\sum$ Nilai $=35$ & & $\sum \mathrm{SK}=104$ \\
\hline
\end{tabular}

Keterangan:

Nilai rata-rata sebelum diberi bobot adalah $35 / 6=5,833$

Nilai rata-rata setelah diberi bobot adalah $104 / 35=2$, 971

2) Menentukan Skor Pada Soal Objektif

Tes Objektif adalah tes yang dalam pemeriksaannya dapat dilakukan secara objektif. Macam-macam tes objektif. 6

a) Tes Benar-Salah (Tru-False)

Soal-soalnya berupa pernyataan-pernyataan (statement). Statement ada yang benar dan ada yang salah. Ada dua rumus untuk mencari skor akhir bentuk tes benar-salah yaitu:

(1) Dengan denda

$\mathrm{S}=\mathrm{R}-\mathrm{W}$

$\mathrm{S}=$ skor yang diperoleh

$\mathrm{R}=$ jawaban yang benar

$\mathrm{W}=$ jawaban yang salah

Contoh: Jumlah soal tes 20 nomor. A menjawab betul 16 nomor dan salah 4 nomor. Maka skor untuk A adalah: $16-4=12$

${ }^{6}$ Suharsimi Arikunto, Dasar-Dasar Evaluasi.....hlm. 179 - 191. 
Khairuddin Alfath, Fajar Fauzi Raharjo : Teknik Pengolahan Hasil Asesmen: Teknik Pengolahan dengan Menggunakan Pendekatan Acuan Norma (PAN) dan

Pendekatan Acuan Patokan (PAP)

(2) Tanpa Denda

Rumus: $\mathrm{S}=\mathrm{R}$, dihitung hanya yang benar.

b) Tes Pilihan ganda

Untuk mengelola skor dalam bentuk pilihan ganda ini digunakan dua macam rumus:

(1) Dengan denda

$$
S=R-\frac{W}{0-1}
$$

$\mathrm{S}=$ skor yang diperoleh

$\mathrm{R}=$ jawaban yang betul

$\mathrm{W}=$ jawaban yang salah

0 = banyaknya option

1 = bilangan tetap

Contoh: murid menjawab betul 17 soal dari 20 soal dengan menggunakan option 4 pilihan.

$$
\text { Skor }=17-\frac{3}{4-1}=16
$$

(2) Tanpa Denda

Rumus: $\mathrm{S}=\mathrm{R}$, dihitung hanya yang benar

c) Tes Menjodohkan

Cara mengelola skornya adalah: $S=R$

$\mathrm{S}=$ skor yang diperoleh

$\mathrm{R}=$ jawaban yang betul

d) Tes Lisan

Cara mengelola skornya adalah: $S=R$

$\mathrm{S}=$ skor yang diperoleh

$\mathrm{R}=$ jawaban yang betul

2. Ranah Psikomotorik

Salah satu instrumen yang sering digunakan untuk menilai hasil belajar keterampilan adalah rubric. Teknik pemberian skor dengan rubrik adalah dengan menulis skor 
Khairuddin Alfath, Fajar Fauzi Raharjo : Teknik Pengolahan Hasil Asesmen: Teknik Pengolahan dengan Menggunakan Pendekatan Acuan Norma (PAN) dan Pendekatan Acuan Patokan (PAP)

pada setiap indikator kemampuan sesuai dengan yang dapat ditampilkan oleh peserta didik. Kemudian skor di setiap aspek tersebut dijumlahkan untuk mendapatkan skor total dari masing-masing peserta didik. ${ }^{7}$

Contoh:

Satuan pendidikan : Madrasah Tsanawiyah

Kelas/Semester : VII/1

Mata Pelajaran : Thaharah

\begin{tabular}{|l|l|l|l|l|l|l|}
\hline \multirow{2}{*}{ No. } & \multirow{2}{*}{ Nama } & \multicolumn{4}{|c|}{ Aspek yang dinilai } & \multirow{2}{*}{ Total skor } \\
\cline { 3 - 6 } & & A & B & C & D & \\
\hline 1. & Adam & 3 & 4 & 3 & 5 & 15 \\
\hline 2. & Idris & 4 & 5 & 5 & 4 & 18 \\
\hline 3. & Nuh & 4 & 3 & 5 & 4 & 16 \\
\hline Dst. & & & & & & \\
\hline
\end{tabular}

Keterangan:

Aspek yang dinilai: $\mathrm{A}=$ Kemampuan melafalkan niat wudhu

$\mathrm{B}=$ Kemampuan berwudhu

$\mathrm{C}=$ Kemampuan melafalkan niat tayamum

$\mathrm{D}=$ Kemampuan bertayamum

Pedoman penskoran: Sangat baik : 5

$\begin{array}{ll}\text { Baik } & : 4 \\ \text { Cukup } & : 3 \\ \text { Kurang } & : 2 \\ \text { Sangat kurang } & : 1\end{array}$

3. Ranah Sikap

Pada hasil belajar afektif, instrumen yang digunakan adalah berupa skala penilaian dan pedoman pengamatan. Pada umumnya, skala penilaian tersebut menggunakan skala

7 Ibid.., 250. 
Khairuddin Alfath, Fajar Fauzi Raharjo : Teknik Pengolahan Hasil Asesmen: Teknik Pengolahan dengan Menggunakan Pendekatan Acuan Norma (PAN) dan

Pendekatan Acuan Patokan (PAP)

likert dengan rentangan 3 , 4, atau 5 yang kemudian ditafsirkan menggunakan kategori verbal seperti sangat tinggi, tinggi, cukup, rendah, dan sangat rendah atau dengan menggunakan sangat baik, baik, sedang, kurang, dan sangat kurang. ${ }^{8}$

Contoh:

\section{Pedoman Observasi Sikap Jujur}

Kelas/ Semester : X/ Ganjil

Tanggal Pengamatan : 5 Januari 2018

\begin{tabular}{|c|c|c|c|c|c|c|c|c|c|c|c|c|c|c|}
\hline \multirow[b]{2}{*}{ No } & \multirow[b]{2}{*}{ Nama } & \multicolumn{13}{|c|}{ Sikap } \\
\hline & & 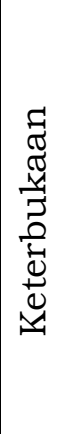 & 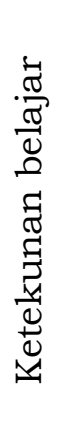 & 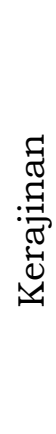 & 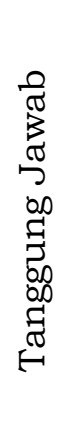 & 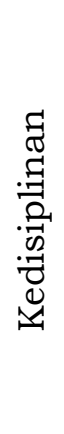 & 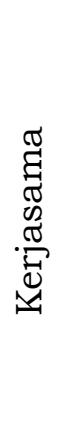 & 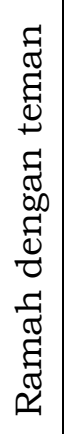 & 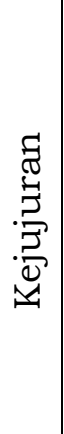 & 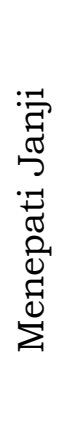 & 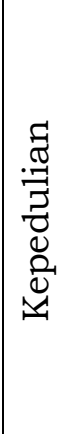 & 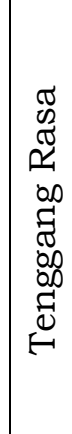 & 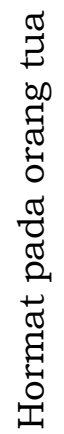 & 亗 \\
\hline 1 & Andri & 3 & 4 & 4 & 3 & 5 & 3 & 3 & 4 & 5 & 3 & 4 & 5 & 46 \\
\hline 2 & Ulul & 3 & 4 & 3 & 4 & 3 & 4 & 5 & 4 & 3 & 4 & 5 & 4 & 46 \\
\hline 3 & Nabil & 4 & 3 & 3 & 4 & 5 & 4 & 3 & 4 & 4 & 4 & 3 & 4 & 45 \\
\hline 4 & Lucinta & 3 & 4 & 5 & 4 & 3 & 4 & 5 & 4 & 3 & 4 & 3 & 3 & 45 \\
\hline 5 & Jojo & 4 & 4 & 3 & 3 & 3 & 4 & 3 & 4 & 5 & 3 & 4 & 4 & 44 \\
\hline & $\mathrm{dst}$ & & & & & & & & & & & & & \\
\hline
\end{tabular}

\section{Pedoman penskoran:}

Skala penilaian sikap dibuat dengan rentang antara 1 s.d 5 .

$1=$ sangat kurang

$2=$ kurang konsisten

3 = mulai konsisten

$4=$ konsisten

5 = selalu konsisten ${ }^{9}$

8 Ibid., 246. hlm 62.

9 Permendikbud No. 81A Tahun 2013 Tentang Implementasi Kurikulum, 
Khairuddin Alfath, Fajar Fauzi Raharjo : Teknik Pengolahan Hasil Asesmen: Teknik Pengolahan dengan Menggunakan Pendekatan Acuan Norma (PAN) dan Pendekatan Acuan Patokan (PAP)

Tahapan selanjutnya yaitu melakukan pedoman penafsiran dengan langkah-langkah sebagai berikut:

a. Menghitung skor terendah

Skor terendah diperoleh dengan mengalikan skor terendah dari masing-masing indikator.

Contohnya:

Skor terendah = 1 (sangat kurang)

Indikator yang dinilai $=12$ (berdasarkan contoh di atas)

Jadi, skor terendah adalah 1 x $12=12$

b. Menghitung skor tertinggi

Skor tertinggi diperoleh dengan mengalikan skor tertinggi masing-masing indikator.

Contohnya:

Skor tertinggi $=5$ (selalu konsisten)

Indikator yang dinilai $=12$ (berdasarkan contoh di atas)

Jadi, skor tertinggi adalah 5 x $12=60$

c. Menghitung selisih skor

Selisih skor diperoleh dari skor tertinggi dikurangi skor terendah.

Jadi, selisih skor adalah $60-12=48$

d. Menentukan jumlah kategori

Jumlah kategori ini sebaiknya sebanding dengan pedoman penskoran awal. Dalam contoh tersebut jumlah kategori ada 5 (sangat kurang, kurang konsisten, mulai konsisten, konsisten, selalu konsisten). Oleh karena ini, jumlah kategori disini sama dengan kategori tersebut.

e. Menentukan rentangan kategori 
Khairuddin Alfath, Fajar Fauzi Raharjo : Teknik Pengolahan Hasil Asesmen: Teknik Pengolahan dengan Menggunakan Pendekatan Acuan Norma (PAN) dan

Pendekatan Acuan Patokan (PAP)

Rumus yang digunakan:

$$
\text { Rentangan }=\frac{\text { Skor tertinggi }- \text { Skor terendah }}{\text { Banyak Kategori }}
$$

Skor yang diperoleh $\frac{60-12}{5}=9,6$

Jadi, rentangan masing-masing kategori adalah 9,6. Ini berarti setiap kategori memuat 9,6 skor. Untuk menetapkan skor masing-masing kategori dapat dimulai dari skor terendah ataupun skor tertinggi. Contohnya sebagai berikut:

$\begin{array}{ll}\text { Sangat kurang } & =12-21 \\ \text { Kurang konsisten } & =22-31 \\ \text { Mulai konsisten } & =32-41 \\ \text { Konsisten } & =42-51 \\ \text { Selalu konsisten } & =52-60\end{array}$

Langkah terakhir adalah dengan memberikan pemaknaan atau penafsiran terhadap siswa. Contoh pada skor Lisa (berdasarkan contoh) mendapatkan 46, jika dilihat pada rentang skor, Lisa berada pada rentang 42 51 , berarti sikap Lisa dalam penilaian tersebut tergolong konsisten. ${ }^{10}$

2. Pendekatan Penilaian Acuan Normatif (PAN)

a. Konsep Pendekatan Penilaian

Penilaian Acuan Norma (PAN) adalah penilaian yang membandingkan hasil belajar siswa terhadap hasil belajar siswa lain dalam kelompoknya. PAN adalah membandingkan skor yang diperoleh peserta didik dengan standar atau norma relatif. ${ }^{11}$ Karena apabila seorang siswa yang terjun ke kelompok A termasuk "Hebat",

10 Sukiman, Pengembangan Sistem Evaluasi..., hlm. 249.

11 Zaenal Arifin, Evaluasi Pembelajaran, (Bandung : PT. Rosdakarya, 2009), hlm. 233. 
Khairuddin Alfath, Fajar Fauzi Raharjo : Teknik Pengolahan Hasil Asesmen: Teknik Pengolahan dengan Menggunakan Pendekatan Acuan Norma (PAN) dan Pendekatan Acuan Patokan (PAP)

mungkin jika pindah ke kelompok lainnya hanya menduduki kualitas "Sedang saja".12 Pendekatan penilaian ini dapat dikatakan sebagai pendekatan "apa adanya" dalam arti bahwa patokan pembanding sematamata diambil dari kenyataan-kenyataan yang diperoleh pada saat pengukuran/ penilaian berlangsung, yaitu hasil belajar siswa yang diukur. PAN tidak dikaitkan sama sekali dengan patokan-patokan yang ada di luar hasil pengukuran sekelompok siswa.

Pendekatan ini menggunakan cara membandingkan prestasi atau skor mentah peserta didik dengan sesama peserta didik dalam kelompok/kelasnya sendiri. Makna nilai dalam bentuk angka maupun kualifikasi memiliki sifat relatif, artinya bila sudah berhasil menyusun pedoman konversi skor berdasarkan tes yang sudah dilakukan pada suatu kelas/kelompok maka pedoman itu hanya berguna bagi kelompok/kelas itu dan kemungkinan besar pedoman itu tidak berguna bagi kelompok/kelas lain karena distribusi skor peserta tes sudah lain. Kecuali, pada saat pengolahan skor kelompok/kelas yang lain tadi disatukan dengan kelompok/kelas pertama. ${ }^{13}$

Penilaian acuan norma adalah menskor nilai peserta didik dengan membandingkan hasil belajar satu peserta dengan hasil peserta lainnya dalam satu kelompok kelas. ${ }^{14}$ Penilaian Acuan Normatif (PAN)

12 Suharsimi Arikunto, Dasar-dasar Evaluasi Pendidikan, (Jakarta : Bumi Aksara, 2003), hlm. 238.

13 Muhamad Afandi, Evaluasi Pembelajaran Sekolah Dasar, (Semarang: Penerbit Unissula Press, 2013), hlm. 85

${ }^{14}$ Zaenal Arifin., Evaluasi ..., hlm. 240. 
Khairuddin Alfath, Fajar Fauzi Raharjo : Teknik Pengolahan Hasil Asesmen: Teknik Pengolahan dengan Menggunakan Pendekatan Acuan Norma (PAN) dan

Pendekatan Acuan Patokan (PAP)

merupakan pendekatan klasik, karena tampilan pencapaian hasil belajar siswa pada suatu tes dibandingkan dengan penampilan siswa lain yang mengikuti tes yang sama. Pengukuran ini digunakan sebagai metode pengukuran yang menggunakan prinsip belajar kompetitif. ${ }^{15}$

Berdasarkan pengertian di atas, dapat disimpulkan bahwa penilaian acuan normatif (PAN) adalah penilaian yang dilakukan dengan mengacu pada norma kelompok; nilai-nilai yang diperoleh siswa diperbandingkan dengan nilai-nilai siswa yang lain, yang termasuk dalam kelompok itu. ${ }^{16}$

Dalam PAP, makna angka (skor) seorang peserta didik ditemukan dengan cara membandingkan hasil belajarnya dengan hasil belajar peserta didik lainnya dalam satu kelompok atau kelas. Peserta didik dikelompokkan berdasarkan jenjang hasil belajar sehingga dapat diketahui kedudukan relative seorang peserta didik jika dibandingkan dengan teman sekelasnya.

Tujuan penilaian acuan norma ini adalah untuk membedakan peserta didik atas kelompok-kelompok tingkat kemampuan, mulai dari yang terendah sampai dengan yang tertinggi. Secara ideal, pendistribusian tingkat kemampuan dalam satu kelompok menggambarkan suatu kurva normal. ${ }^{17}$

15 Sukardi, Evaluasi Pendidikan Prinsip dan Operasionalnya, (Jakarta: Bumi Aksara, 2008), hlm. 59.

16 Elis Ratnawulan dan Rusdiana, Evaluasi Pembelajaran.....hlm. 237.

17 Nana Sudjana, Penilaian Hasil Proses Belajar Mengajar, (Bandung : PT Remaja Rosdakarya: 1995), hlm. 93. 

Pengolahan dengan Menggunakan Pendekatan Acuan Norma (PAN) dan Pendekatan Acuan Patokan (PAP)

b. Kriteria Penyusunan Penilaian Acuan Normatif (PAN)

1) Tidak ditekankan untuk mengukur penampilan yang eksak dari behavioral objectives. Dengan kata lain, soal-soal pada PAN tidak didasarkan atas pengajaran yang diterima siswa atau atas keterampilan atau tingkah laku yang diidentifikasikan sebagai sesuatu yang dianggap relevan bagi belajar siswa.

2) Pada proses belajar, penilaian nilai normatif pada umumnya banyak dilakukan oleh seorang guru.

3) Penekanan dalam penilaian untuk proses belajar, seseorang mengacu pada ketentuan atau norma yang berlaku disekolah.

4) Seorang guru dapat menggunakan acuan normatif nasional.

c. Ciri-ciri Acuan Penilaian Normatif (PAN)

1) Penilaian acuan normatif digunakan untuk mengetahui kemampuan peserta didik dalam komunitasnya, seperti di kelas, sekolah, dan sebagainya.

2) Penilaian acuan normatif menggunakan kriteria yang bersifat relative.

3) Nilai hasil dari penilaian acuan normatif digunakan untuk menunjukan kedudukan peserta didik (peringkatnya) dalam komunitasnya (kelompoknya).

4) Penilaian normatif memiliki kecendrungan untuk menggunakan rentangan tingkat penguasaan seseorang terhadap kelompoknya, mulai dari yang sangat istimewa sampai dengan yang mengalami kesulitan yang serius. 
Khairuddin Alfath, Fajar Fauzi Raharjo : Teknik Pengolahan Hasil Asesmen: Teknik Pengolahan dengan Menggunakan Pendekatan Acuan Norma (PAN) dan

Pendekatan Acuan Patokan (PAP)

d. Teknik dan Prosedur Pengolahan Skor dengan PAN dalam Microsoft Excel

Diketahui skor ujian siswa (setelah dihitung dengan bobotnya) kelas XII IPS A MANU al-Bassam sebagaimana dalam tabel berikut:

\begin{tabular}{|c|l|c|c|c|}
\hline No. & Nama & PG & Isian & Uraian \\
\hline 1 & Ari & 75 & 75 & 80 \\
\hline 2 & Agus & 85 & 80 & 80 \\
\hline 3 & Anji & 90 & 90 & 95 \\
\hline 4 & Bibil & 80 & 80 & 80 \\
\hline 5 & Kibil & 90 & 90 & 90 \\
\hline 6 & Lucinta & 95 & 95 & 90 \\
\hline 7 & Luna & 90 & 95 & 90 \\
\hline 8 & Safik & 75 & 80 & 70 \\
\hline 9 & Cinta & 70 & 80 & 70 \\
\hline 10 & Dia & 80 & 75 & 80 \\
\hline
\end{tabular}

Berikut langkah pengolahan skor di atas dengan PAN dalam Microsoft excel:

1) Buat tabel seperti tabel di atas

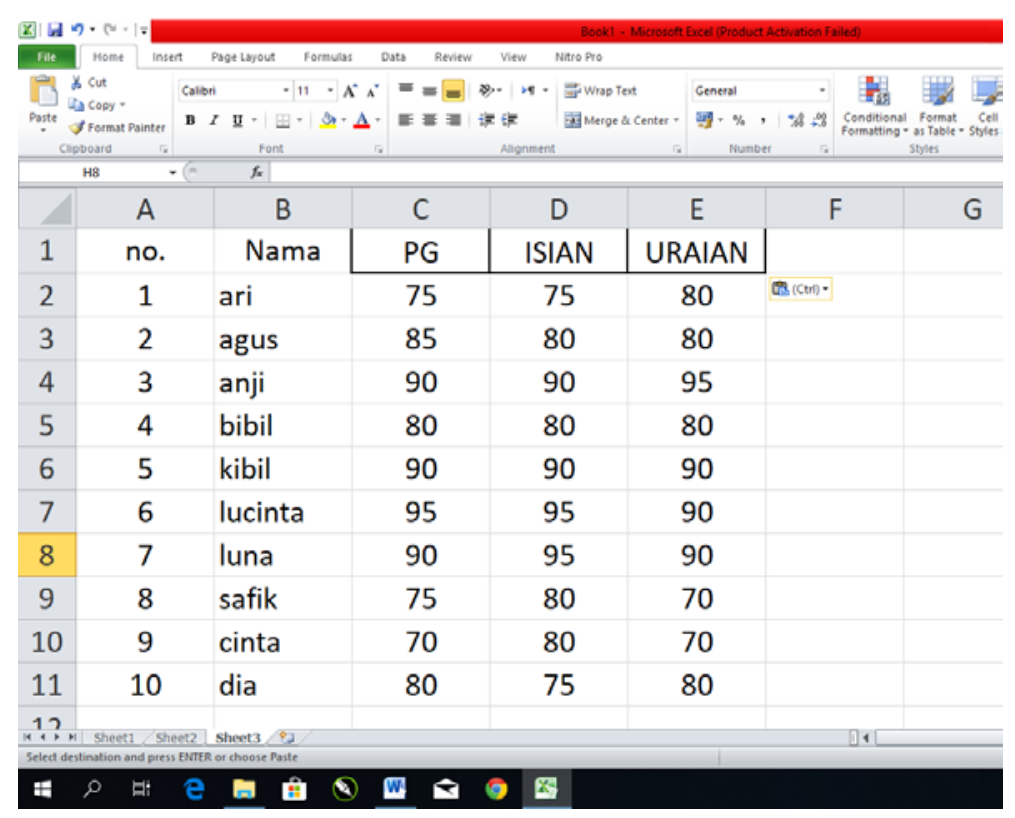


Khairuddin Alfath, Fajar Fauzi Raharjo : Teknik Pengolahan Hasil Asesmen: Teknik Pengolahan dengan Menggunakan Pendekatan Acuan Norma (PAN) dan Pendekatan Acuan Patokan (PAP)

2) Kemudian buat kolom skor rata-rata, mean dan standar deviasi, nilai PAN dan Kriteran PAN sebagai berikut.

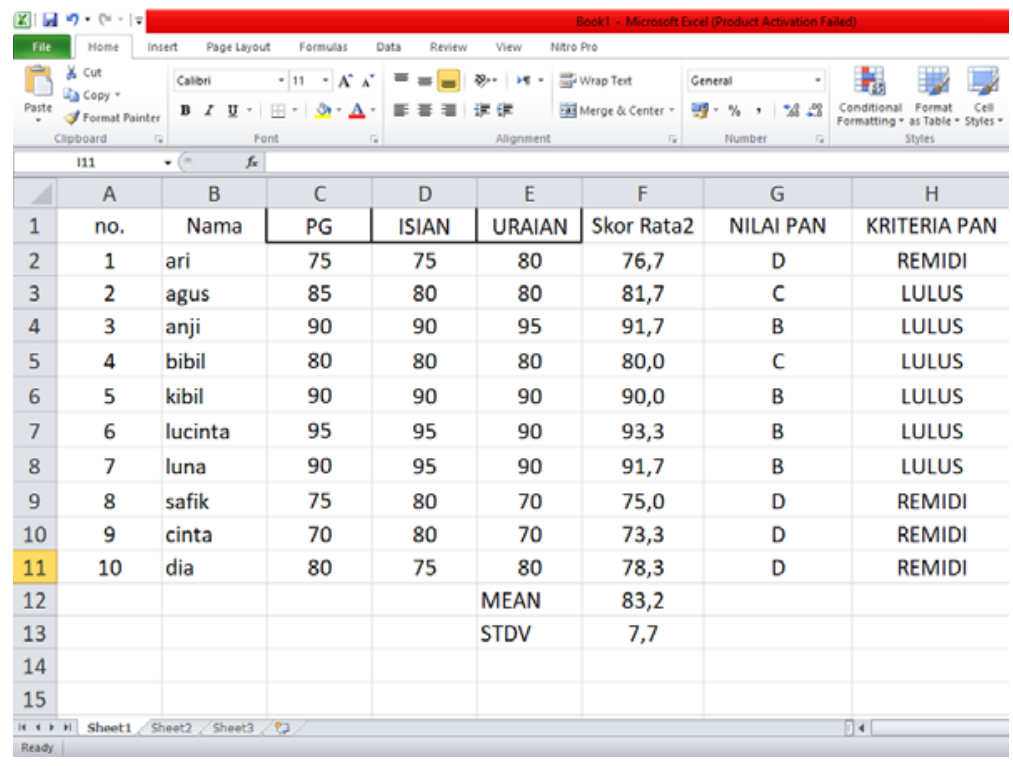

Langkahnya:

a) Buat di kolom F, menu Skor Rata2, dan carilah skor rata-ratanya dengan cara klik di sel F: $=$ AVERAGE $(\mathrm{C} 2: \mathrm{E} 2)$. Kemudian tarik titik kotak pojok sampai $\mathrm{F} 11$.

b) Mencari mean dari skor rata. Buat kolom mean di sel E 12. Kemudian klik di sel F 12: $=$ AVERAGE $(\mathrm{F} 2: \mathrm{F} 11)$.

c) Mencari standar deviasi. Buat kolom standar deviasi pada sel 13 E. kemudian klik di sel F 13: $=\operatorname{STDEV}(\mathrm{F} 2: \mathrm{F} 11)$.

d) Setelah membuat kolom PAN di G 1, diolah skor tersebut dengan PAN dengan ketentuan berikut:

$A \geq \bar{x}+1,5 S D$

$$
\bar{x}+0,5 S D \leq B<\bar{x}+1,5 S D
$$


Khairuddin Alfath, Fajar Fauzi Raharjo : Teknik Pengolahan Hasil Asesmen: Teknik Pengolahan dengan Menggunakan Pendekatan Acuan Norma (PAN) dan

Pendekatan Acuan Patokan (PAP)

$$
\begin{aligned}
& \bar{x}-0,5 S D \leq C<\bar{x}+0,5 S D \\
& \bar{x}-1,5 S D \leq D<\bar{x}+0,05 S D \\
& E<\bar{x}-1,5 S D
\end{aligned}
$$

Adapun langkahnya adalah klik pada sel G2 dengan rumus:

$=\mathrm{IF}(\mathrm{F} 2<\$ \mathrm{~F} \$ 12-(3 / 2) * \$ \mathrm{~F} \$ 13 ; " \mathrm{E} " ; \mathrm{IF}(\mathrm{F} 2<\$ \mathrm{~F} \$ 12-$

$(1 / 2) * \$ F \$ 13 ; " D " ; I F(F 2<\$ F \$ 12+(1 / 2) * \$ F \$ 13 ; " C " ; I F(F$

$2<\$ F \$ 12+(3 / 2) * \$ F \$ 13 ; " B " ; " A "))))$

Kemudian tarik titik kotak pojok sel G2 sampai G 11.

e) Untuk kriteria PAN, misalnya

\section{Lulus : nilai $\mathbf{C}$; remidi: nilai $<\mathbf{C}$}

Adapun langkahnya, klik pada sel H2, tulis rumus: $=\mathrm{IF}(\mathrm{F} 2<$ <F $\$ 12-(1 / 2) * \$ F \$ 13 ; " R E M I D I " ; " L U L U S ")$

Kemudian tarik titik kotak pojok sel H2 sampai $\mathrm{H}$ 11.

3. Penilaian Acuan Patokan (PAP)

a. Pengertian

Penilaian Acuan Patokan (PAP) atau Criterion Referenced Evaluation adalah model pendekatan penilaian yang mengacu kepada suatu kriteria pencapaian tujuan (TKP) yang telah ditetapkan sebelumnya. ${ }^{18}$ Penilaian Acuan Patokan (PAP) adalah pendekatan penilaian yang membandingkan hasil pengukuran terhadap mahasiswa dengan patokan "batas lulus" yang ditetapkan untuk masing-masing bidang mata pelajaran. ${ }^{19}$ PAP adalah

\footnotetext{
18 Materi Kuliah Evaluasi Pembelajaran, dalam http:/ / staffnew.uny.ac.id/upload/132231727/ pendidikan/MATERI+PANPAP.pdf, diakses pada Kamis, 29 Desember 2018, 18.30 WIB.

19 Asmawi Zainul dan Noehi Nasution, Penilaian Hasil Belajar, (Jakarta: PAU-PPAI, 1997), hal. 146.
} 
Khairuddin Alfath, Fajar Fauzi Raharjo : Teknik Pengolahan Hasil Asesmen: Teknik Pengolahan dengan Menggunakan Pendekatan Acuan Norma (PAN) dan Pendekatan Acuan Patokan (PAP)

membandingkan skor yang diperoleh peserta didik dengan suatu standar atau norma absolut. 20

Jadi, PAP meneliti apa yang dapat dikerjakan oleh peserta didik dan bukan membandingkan seorang peserta didik dengan teman sekelasnya, melainkan dengan suatu kriteria atau patokan yang spesifik. Kriteria yang dimaksud adalah suatu tingkat pengalaman belajar atau sejumlah kompetensi dasar yang telah ditetapkan terlebih dahulu sebelum kegiatan belajar berlangsung. ${ }^{21}$ Misalnya, kriteria yang digunakan $75 \%$ atau $80 \%$. Bagi peserta didik yang kemampuannya dibawah kriteria yang telah ditetapkan dinyatakan tidak berhasil dan harus mendapatkan remedial.

b. Tujuan PAP dan Manfaat PAP

Tujuan PAP adalah untuk mengukur secara pasti tujuan atau kompetensi yang ditetapkan sebagai kriteria keberhasilannya. PAP sangat bermanfaat dalam upaya meningkatkan kualitas hasil belajar sebab peserta didik diusahakan untuk mencapai standar yang telah ditentukan, dan hasil belajar peserta didik dapat diketahui derajat pencapaiannya. Untuk menentukan batas lulus (passing grade) dengan pendekatan ini, setiap skor peserta didik dibandingkan dengan skor ideal yang mungkin dicapai oleh peserta didik. ${ }^{22}$

Menurut Payne (1974) dalam bukunya Asmawi Zainul, penerapan PAP dapat dimanfaatkan antara lain:

20 Zaenal Arifin., Evaluasi Pembelajaran., 2009., Bandung : PT. Rosdakarya.,hlm. 233.

21 Ibid., hlm. 233.

22 Zainal Arifin, Penelitian..., hlm. 233. 
Khairuddin Alfath, Fajar Fauzi Raharjo : Teknik Pengolahan Hasil Asesmen: Teknik Pengolahan dengan Menggunakan Pendekatan Acuan Norma (PAN) dan

Pendekatan Acuan Patokan (PAP)

1) Penempatan seseorang dalam rentetan kegiatan belajar.

2) Untuk mendiagnosis kemampuan seseorang dalam pembelajaran.

3) Jika dilakukan secara periodik dapat digunakan untuk memonitor kemajuan setiap anak didik dalam proses pembelajaran. Secara berkelanjutan dapat diketahui status seseorang dalam satu rentetan kegiatan belajar. Akhirnya dapat memacu atau memotivasi semangat belajar siswa.

4) Kemampuan masing-masing anak didik untuk menyelesaikan kurikulum secara kumulatif akan dapat menentukan keterlaksanaan kurikulum. ${ }^{23}$

c. Penerapan PAP

Pendekatan PAP tidak berorientasi pada "apa adanya". Pertama, pendekatan ini mempergunakan angka rata-rata dengan terlebih dahulu menetapkan kriteria keberhasilan, yaitu "batas lulus" penguasaan bahan pelajaran atau kriteria pencapaian tujuan (TKP). Siswa yang telah mencapai batas ini dianggap telah berhasil dalam belajar dan diperkenankan mempelajari bahan pelajaran yang lebih tinggi, sedangkan yang belum mencapai batas tersebut dianggap belum berhasil dan diharuskan memantapkan kembali pelajarannya itu. Kedua, dalam proses pengajaran, tenaga pengajar tidak begitu saja membiarkan siswa menjalani sendiri proses belajarnya, melainkan terus-menerus secara langsung ataupun tidak langsung merangsang dan memeriksa kemajuan belajar siswa serta membantunya melewati

23 Asmawi Zainul dan Noehi Nasution, Penilaian ..., hlm. 149-150. 
Khairuddin Alfath, Fajar Fauzi Raharjo : Teknik Pengolahan Hasil Asesmen: Teknik Pengolahan dengan Menggunakan Pendekatan Acuan Norma (PAN) dan Pendekatan Acuan Patokan (PAP)

tahap-tahap pengajaran secara berhasil. ${ }^{24}$ Penggunaan tes formatif dalam penilaian ini sangat mendukung untuk mengetahui keberhasilan belajar siswa.

Adapun rumus yang digunakan untuk mengolah nilai dengan PAP adalah sebagai berikut:

Rentangan $=\frac{\text { Skor Rill }}{\text { Skor Maksimum Ideal }} \times 100$ Keterangan:

Skor Rill

: Skor yang berhasil dicapai oleh siswa

Skor Maksimum Ideal : Skor yang mungkin dapat dicapai siswa apabila mampu menjawab secara benar semua soal ujian

100 : Skala yang dipakai $(0-100)^{25}$

d. Teknik dan Prosedur Pengolahan Skor dengan PAP dalam Microsoft Excel

Misal data skor ini sama dengan data skor PAN di atas. Sehingga hasil pengolahan skornya dengan pendekatan PAP adalah sebagai berikut:

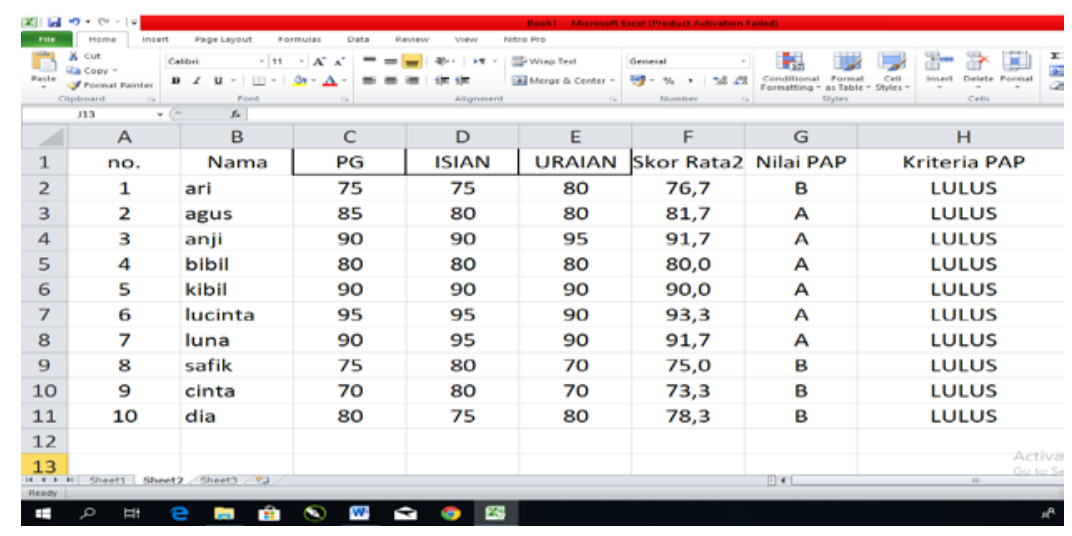

24 Suryadi, Pendekatan dalam Penilaian, hlm. 3., dalam http:/ / file.upi.edu/Direktori/FIP/JUR._ADMINISTRASI_PENDIDIKAN/ 1968072 91998021-SURYADI/PENDEKATAN_DALAM_PENILAIAN.pdf, diakses pada Kamis, 29 Desember 2018, 18.30 WIB.

25 Sukiman, Pengembangan ..., hlm. 253. 
Khairuddin Alfath, Fajar Fauzi Raharjo : Teknik Pengolahan Hasil Asesmen: Teknik Pengolahan dengan Menggunakan Pendekatan Acuan Norma (PAN) dan

Pendekatan Acuan Patokan (PAP)

Adapun untuk menentukan nilai PAP misalnya mengacu pada patokan berikut:

\begin{tabular}{|l|l|}
\hline \multicolumn{2}{|l}{ Patokan Nilai } \\
\hline A: & Skor Rata2 $\geq 80$ \\
\hline B: & $70 \leq$ skor rata2 $<80$ \\
\hline C: & $55 \leq$ skor rata2 $<70$ \\
\hline D: & $40 \leq$ skor rata2 $<55$ \\
\hline E: & skor rata2 $<40$ \\
\hline
\end{tabular}

Kemudian pada sel G2 ditulis rumus:

=IF(F2<40;"E"; $\mathrm{IF}(\mathrm{F} 2<55 ; " \mathrm{D}$; $\mathrm{IF}(\mathrm{F} 2<70 ; " \mathrm{C}$ " $\mathrm{IF}(\mathrm{F} 2<80 ; " \mathrm{~B}$;"A"))))

Selanjutnya tarik titik kotak pojok sel G2 sampai G 11 .

Setelah itu menentukan kriteria kelulusan dengan

ketentuan sebagai berikut.

\begin{tabular}{|c|c|}
\hline Lulus: & nilai $\geq \mathrm{C}$ \\
\hline Remidi: & nilai $<\mathrm{C}$ \\
\hline
\end{tabular}

Kemudian pada sel $\mathrm{H} 2$ ditulis rumus:

$=\mathrm{IF}$ (F2<55;"REMIDI";"LULUS")

Selanjutnya tarik titik kotak pojok sel H2 sampai H 11.

e. Perbedaan PAN dan PAP Serta Kelebihan dan Kekurangannya

1) Pengembangan tes

\begin{tabular}{|l|l|l|l|}
\hline \multicolumn{2}{|c|}{ CRT (PAP) } & \multicolumn{2}{c|}{ NRT (PAN) } \\
\hline No. & \multicolumn{1}{|c|}{$\begin{array}{l}\text { NRT hanya terdiri dari soal-soal } \\
\text { tes yang didasarkan pada } \\
\text { tujuan khusus pembelajaran }\end{array}$} & 1. & $\begin{array}{l}\text { Soal tes tidak hanya } \\
\text { berdasarkan pelajaran yang } \\
\text { diterima siswa }\end{array}$ \\
\hline 2. & $\begin{array}{l}\text { Setiap tes mempunyai prasarat } \\
\text { agar siswa menunjukkan } \\
\text { "performance" seperti yang } \\
\text { tercantum dalam TIK }\end{array}$ & 2. & $\begin{array}{l}\text { Tidak perlu terlebih dahulu } \\
\text { menentukan secara pasti } \\
\text { performance yang diharapkan } \\
\text { sebelum tes disusun }\end{array}$ \\
\hline 3. & $\begin{array}{l}\text { Dasar pertimbangan untuk } \\
\text { diterimanya performance } \\
\text { tertentu harus berdasarkan } \\
\text { pada kriteria tertentu }\end{array}$ & 3. & $\begin{array}{l}\text { Dasar pertimbangan } \\
\text { diterimanya performance } \\
\text { berdasarkan hasil perolehan } \\
\text { nilai yang didapat oleh siswa }\end{array}$ \\
\hline 4. & $\begin{array}{l}\text { Mementingkan butir tes sesuai } \\
\text { dg perilaku (tujuan } \\
\text { pembelajaran) }\end{array}$ & 4. & $\begin{array}{l}\text { Membuat tes dalam kategori } \\
\text { sedang }\end{array}$ \\
\hline
\end{tabular}


Khairuddin Alfath, Fajar Fauzi Raharjo : Teknik Pengolahan Hasil Asesmen: Teknik Pengolahan dengan Menggunakan Pendekatan Acuan Norma (PAN) dan Pendekatan Acuan Patokan (PAP)

2) Standar penilaian performance siswa

\begin{tabular}{|l|l|l|l|}
\hline \multicolumn{2}{|c|}{ CRT (PAP) } & \multicolumn{2}{c|}{ NRT (PAN) } \\
\hline No. & \multicolumn{1}{|c|}{ No. } & \multicolumn{1}{|c|}{} \\
\hline 1. & $\begin{array}{l}\text { Standar performance ditentukan } \\
\text { dalam bentuk tingkah laku }\end{array}$ & 1. & $\begin{array}{l}\text { Standar performance } \\
\text { berdasarkan pada jumlah } \\
\text { pertanyaan yang dijawab benar } \\
\text { oleh siswa dihubungkan dengan } \\
\text { siswa lain yang menempuh tes } \\
\text { tersebut. }\end{array}$ \\
\hline 2. & $\begin{array}{l}\text { Pengukur performance dalam } \\
\text { menempuh tes didasarkan pada } \\
\text { standar performance yang telah } \\
\text { ditetapkan }\end{array}$ & 2. & $\begin{array}{l}\text { Prestasi siswa adalah 80\% dari } \\
\text { siswa lain }\end{array}$ \\
\hline 3. & $\begin{array}{l}\text { Distribusi nilai tidak menyerupai } \\
\text { kurve normal }\end{array}$ & 3. & $\begin{array}{l}\text { Penilaian didasarkan pada apa } \\
\text { adanya hasil prestasi siswa }\end{array}$ \\
\hline 4. & $\begin{array}{l}\text { Didasarkan pada batas } \\
\text { kelulusan (KKM) }\end{array}$ & 4. & $\begin{array}{l}\text { Perolehan nilai berdasarkan } \\
\text { pada kelompok/kelas. }\end{array}$ \\
\hline
\end{tabular}

3) Maksud tes

\begin{tabular}{|l|l|l|l|}
\hline \multicolumn{2}{|c|}{ CRT (PAP) } & \multicolumn{2}{c|}{ NRT (PAN) } \\
\hline No. & \multicolumn{1}{|c|}{} & No. & \\
\hline 1. & $\begin{array}{l}\text { Dimaksudkan untuk } \\
\text { mengklasifikasikan seseorang, } \\
\text { mendiagnosa belajar siswa }\end{array}$ & 1. & $\begin{array}{l}\text { Untuk mengadakan seleksi pada } \\
\text { individu/membuat rangki } \\
\text { ng }\end{array}$ \\
\hline
\end{tabular}

f. Kelebihan dan Kekurangan PAN dan PAP

Kelebihan PAN adalah sebagai berikut:

1) Dapat digunakan untuk menetapkan nilai secara maksimal.

2) Dapat membedakan kemampuan peserta didik yang pintar n kurang pintar. Membedakan kelompok atas dan bawah.

3) Fleksibel : dapat menyesuaikan dengan kondisi yang berbeda-beda

4) Mudah menilai karena tidak ada patokan.

5) Dapat digunakan untuk menilai ranah kognitif, afektif dan psikomotor. ${ }^{26}$

26 Suryadi, Pendekatan dalam Penilaian, hlm. 3., dalam http://file.upi.edu/Direktori/FIP/JUR._ADMINISTRASI_PENDIDIKAN/ 1968072 
Khairuddin Alfath, Fajar Fauzi Raharjo : Teknik Pengolahan Hasil Asesmen: Teknik Pengolahan dengan Menggunakan Pendekatan Acuan Norma (PAN) dan

Pendekatan Acuan Patokan (PAP)

Adapun kelebihan PAP adalah sebagai berikut:

1) Dapat membantu guru merancang program remidi.

2) Tidak membutuhkan perhitungan statistic yang rumit.

3) Dapat mengukur ketercapaian tujuan pembelajaran.

4) Nilainya bersifat tetap selama standar yang digunakan sama.

5) Hasil penilaian dapat digunakan untuk umpan balik atau untuk mengetahui apakah tujuan pembelajaran sudah tercapai atau belum.

6) Banyak digunakan untuk kelas dengan materi pembelajaran berupa konsep.

7) Mudah menilai karena ada patokan. ${ }^{27}$

Selain memiliki kelebihan, kedua pendekatan tersebut memiliki kekurangan. Di antara kekurangan PAN adalah sebagai berikut.

1) Sedikit menyebutkan kompetensi siswa apa yang mereka ketahui atau dapat mereka lakukan.

2) Tidak fair karena peringkat siswa tidak hanya bergantung pada tingkatan prestasi, tetapi juga atas prestasi siswa lain.

3) Tidak dapat diandalkan siswa yang gagal sekarang mungkin dapat lulus tahun berikutnya. ${ }^{28}$

91998021-SURYADI/PENDEKATAN_DALAM_PENILAIAN.pdf, diakses pada Kamis, 29 Desember 2018, 18.30 WIB.

27 Suryadi, Pendekatan dalam Penilaian, hlm. 3., dalam http:/ / file.upi.edu/Direktori/FIP/JUR._ADMINISTRASI_PENDIDIKAN/ 1968072 91998021-SURYADI/PENDEKATAN_DALAM_PENILAIAN.pdf, diakses pada Kamis, 29 Desember 2018, 18.30 WIB. hlm. 103 .

28 Aunurrahma, Belajar dan Pembelajaran, (Bandung: CV Alfabeta, 2009), 
Khairuddin Alfath, Fajar Fauzi Raharjo : Teknik Pengolahan Hasil Asesmen: Teknik Pengolahan dengan Menggunakan Pendekatan Acuan Norma (PAN) dan Pendekatan Acuan Patokan (PAP)

4. Kriteria Ketuntasan Minimal (KKM)

a. Konsep KKM

KKM ditentukan oleh satuan pendidikan mengacu pada Standar Kompetensi Lulusan (SKL) dengan mempertimbangkan karakteristik peserta didik, karakteristik mata pelajaran, dan kondisi satuan pendidikan. KKM dirumuskan setidaknya dengan memperhatikan 3 (tiga) aspek, yaitu kompleksitas materi/kompetensi, intake (kualitas peserta didik), serta guru dan daya dukung satuan pendidikan.

1) Aspek karakteristik materi/kompetensi yaitu memperhatikan kompleksitas KD dengan mencermati kata kerja yang terdapat pada KD tersebut dan berdasarkan data empiris dari pengalaman guru dalam membelajarkan KD tersebut pada waktu sebelumnya. Semakin tinggi aspek kompleksitas materi/kompetensi, semakin menantang guru untuk meningkatkan kompetensinya.

2) Aspek intake yaitu memperhatikan kualitas peserta didik yang dapat diidentifikasi antara lain berdasarkan hasil ujian nasional pada jenjang pendidikan sebelumnya, hasil tes awal yang dilakukan oleh sekolah, atau nilai rapor sebelumnya. Semakin tinggi aspek intake, semakin tinggi pula nilai KKM-nya.

3) Aspek guru dan daya dukung antara lain memperhatikan ketersediaan guru, kesesuaian latar belakang pendidikan guru dengan mata pelajaran yang diampu, kompetensi guru (misalnya hasil Uji Kompetensi Guru), rasio jumlah peserta didik dalam satu kelas, sarana prasarana pembelajaran, dukungan 
Khairuddin Alfath, Fajar Fauzi Raharjo : Teknik Pengolahan Hasil Asesmen: Teknik Pengolahan dengan Menggunakan Pendekatan Acuan Norma (PAN) dan

Pendekatan Acuan Patokan (PAP)

dana, dan kebijakan sekolah. Semakin tinggi aspek guru dan daya dukung, semakin tinggi pula nilai KKMnya. ${ }^{29}$

KKM sebaiknya dibuat sama untuk semua mata pelajaran pada semua tingkat kelas, artinya nilai KKM sama untuk semua mata pelajaran pada suatu sekolah. Nilai KKM ditulis dalam dokumen Kurikulum Tingkat Satuan Pendidikan (KTSP) dan disosialisasikan kepada semua warga sekolah. Secara teknis prosedur penentuan KKM mata pelajaran pada Satuan Pendidikan dapat digambarkan pada alur sebagai berikut:

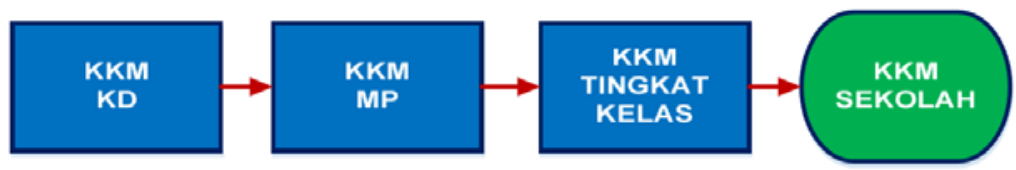

1) Menetapkan KKM setiap kompetensi dasar (KD), yang menggunakan kriteria analisis dengan mempertimbangkan aspek karakteristik peserta didik (intake), karakteristik mata pelajaran (kompleksitas materi/kompetensi), serta guru dan kondisi satuan pendidikan (daya dukung).

2) Menetapkan KKM mata pelajaran yang merupakan rata-rata dari semua KKM kompetensi dasar yang terdapat dalam satu mata pelajaran.

3) Menetapkan KKM pada tingkatan kelas yang merupakan rata-rata dari semua KKM mata pelajaran pada setiap tingkatan kelas.

29 Panduan Penilaian Oleh Pendidik Dan Satuan Pendidikan Untuk Sekolah Menengah Atas, Direktorat Pembinaan Sekolah Menengah Direktorat Jenderal Pendidikan Dasar Kementerian Pendidikan, 2017, hlm. 8-9. Lihat juga, Sukiman, Pengembangan ..., hlm. 258. 
Khairuddin Alfath, Fajar Fauzi Raharjo : Teknik Pengolahan Hasil Asesmen: Teknik Pengolahan dengan Menggunakan Pendekatan Acuan Norma (PAN) dan Pendekatan Acuan Patokan (PAP)

4) Menetapkan KKM satuan pendidikan yang merupakan rata-rata dari semua KKM pada setiap tingkatan kelas $\mathrm{X}$, XI, dan XII dalam satu semester atau satu tahun pembelajaran.

b. Teknik Pengolahan KKM

Terlebih dahulu harus ditentukan suatu kriteria KKM. Misalnya sebagai berikut.

\begin{tabular}{|c|c|c|c|}
\hline \multirow{2}{*}{ Aspek yang dianalisis } & \multicolumn{3}{|c|}{ Kriteria dan Skala Penilaian } \\
\hline \multirow{2}{*}{ Kompleksitas } & Tinggi & Sedang & Rendah \\
& $<65$ & $65-79$ & $80-100$ \\
\hline \multirow{2}{*}{ Guru dan Daya Dukung } & Tinggi & Sedang & Rendah \\
& $80-100$ & $65-79$ & $<65$ \\
\hline \multirow{2}{*}{ Intake peserta didik } & Tinggi & Sedang & Rendah \\
& $80-100$ & $65-79$ & $<65$ \\
\hline
\end{tabular}

Maka penentuan KKM pertingkatannya adalah sebagai berikut.

1) KKM tingkat $\mathrm{KD}$

$\mathrm{KKM}$ per $\mathrm{KD}=\frac{\text { Jumlah skor setiap aspek }}{\text { jumlah aspek }}$

Misal aspek daya dukung mendapat skor 90 aspek kompleksitas mendapat skor 70 aspek intake mendapat skor 65, maka KKM nya:

$\mathrm{KKM}=(90+70+65) / 3=75$.

2) KKM tingkat Mapel

Untuk KKM ini, digunakan rumus:

KKM Mapel $=$ Jumlah KKM per KD / Jumlah KD

3) KKM tingkat Kelas

Untuk KKM ini, digunakan rumus:

KKM Kelas = Jumlah KKM per MP / Jumlah MP kelas

4) KKM satuan pendidikan

Untuk KKM ini, digunakan rumus:

KKM satuan pendidikan $=$ Jumlah KKM per Kelas $/ 3$. 
Khairuddin Alfath, Fajar Fauzi Raharjo : Teknik Pengolahan Hasil Asesmen: Teknik Pengolahan dengan Menggunakan Pendekatan Acuan Norma (PAN) dan

Pendekatan Acuan Patokan (PAP)

\section{KESIMPULAN}

Dari pemaparan singkat di atas, dapat diambil beberapa kesimpulan sebagai berikut:

1. Penilaian acuan patokan adalah penilaian yang mengacu kepada tujuan instruksional atau untuk mengukur tingkat penguasaan peserta didik terhadap perilaku yang terdapat dalam tujuan instruksional khusus tersebut. Penilaian acuan norma adalah penilaian yang mengacu kepada norma untuk menentukan kedudukan atau posisi seorang peserta didik di antara kelompoknya.

2. Persamaan penilaian acuan norma dan acuan patokan antara lain adalah keduanya mempersyaratkan perumusan secara spesifik perilaku yang diukur, disusun dari sampel butirbutir tes yang relevan dan representatif, keduanya dinilai kualitasnya dari segi validitas dan reliabilitas dan digunakan ke dalam pendidikan walaupun untuk maksud yang berbeda.

3. Adapun perbedaan dari kedua penilaian tersebut antara lain:

a. Penilaian acuan norma biasanya mengukur sejumlah besar perilaku khusus dengan sedikit butir tes untuk setiap perilaku. Penilaian acuan patokan biasanya mengukur perilaku khusus dalam jumlah yang terbatas dengan banyak butir tes untuk setiap perilaku.

b. Penilaian acuan norma menekankan perbedaan di antara peserta tes dari segi tingkat pencapaian belajar secara relatif. Penilaian acuan patokan menekankan penjelasan tentang apa perilaku yang dapat dan yang tidak dapat dilakukan oleh setiap peserta tes.

c. Penilaian acuan norma lebih mementingkan butir-butir tes yang mempunyai tingkat kesulitan sedang dan biasanya membuang tes yang terlalu mudah dan terlalu 
Khairuddin Alfath, Fajar Fauzi Raharjo : Teknik Pengolahan Hasil Asesmen: Teknik Pengolahan dengan Menggunakan Pendekatan Acuan Norma (PAN) dan Pendekatan Acuan Patokan (PAP)

sulit. Penilaian acuan patokan mementingkan butir-butir tes yang relevan dengan perilaku yang akan diukur tanpa perduli dengan tingkat kesulitannya.

d. Penilaian acuan norma digunakan terutama untuk survey. Penilaian acuan patokan digunakan terutama untuk penguasaan.

4. KKM dirumuskan setidaknya dengan memperhatikan 3 (tiga) aspek, yaitu kompleksitas materi/kompetensi, intake (kualitas peserta didik), serta guru dan daya dukung satuan pendidikan. Setiap aspke ditentukan bisa dengan skala atau nominal. KKM disusun pada tingkat KD, mapel, kelas, dan satuan pendidkan. 
Khairuddin Alfath, Fajar Fauzi Raharjo : Teknik Pengolahan Hasil Asesmen: Teknik Pengolahan dengan Menggunakan Pendekatan Acuan Norma (PAN) dan

Pendekatan Acuan Patokan (PAP)

\section{DAFTAR PUSTAKA}

Afandi, Muhamad, Evaluasi Pembelajaran Sekolah Dasar, Semarang: Penerbit Unissula Press, 2013.

Arifin, Zaenal Evaluasi Pembelajaran, Bandung : PT. Rosdakarya, 2009.

Arikunto, Suharsimi, Dasar-dasar Evaluasi Pendidikan, Jakarta : Bumi Aksara, 2003.

Aunurrahma, Belajar dan Pembelajaran, Bandung: CV Alfabeta, 2009. Sukiman, Pengembangan Sistem Evaluasi, Insan Madani: Sleman, 2012.

Idris, Daeng, "Teknik Penilaian Pembelajaran Dengan Menggunakan Passing Grade", Jurnal Matematika, Statistika dan Komputasi, vol. IV, No. 1, 26-29 Juli 2017.

Materi Kuliah Evaluasi Pembelajaran, dalam http://staffnew.uny.ac.id/upload/132231727/pendidikan/MA TERI+PAN-PAP.pdf, diakses pada Kamis, 29 Desember 2018, 18.30 WIB.

Panduan Penilaian Oleh Pendidik Dan Satuan Pendidikan Untuk Sekolah Menengah Atas, Direktorat Pembinaan Sekolah Menengah Direktorat Jenderal Pendidikan Dasar Kementerian Pendidikan, 2017.

Sudjana, Nana, Penilaian Hasil Proses Belajar Mengajar, Bandung : PT Remaja Rosdakarya: 1995.

Sukardi, Evaluasi Pendidikan Prinsip dan Operasionalnya, Jakarta: Bumi Aksara, 2008.

Suryadi, Pendekatan dalam Penilaian, hlm. 3., dalam http://file.upi.edu/Direktori/FIP/JUR._ADMINISTRASI_PENDI DIKAN/196807291998021SURYADI/PENDEKATAN_DALAM_PENILAIAN.pdf, diakses pada Kamis, 29 Desember 2018, 18.30 WIB.

Zainul, Asmawi dan Noehi Nasution, Penilaian Hasil Belajar, Jakarta: PAU-PPAI, 1997. 